\title{
Adverse Drug Events in a Sentinel Hospital in the State of Goiás, Brazil
}

\author{
Ana Elisa Bauer de Camargo Silva ${ }^{1}$ \\ Adriano Max Moreira Reis ${ }^{2}$ \\ Adriana Inocenti Miasso ${ }^{3}$ \\ Jânia Oliveira Santos ${ }^{4}$ \\ Silvia Helena De Bortoli Cassiani ${ }^{5}$
}

This was a retrospective, descriptive and documental study with the aim of identifying adverse drug events which occurred in the medication administration process and to classify these medication errors. This study was developed in the internal medicine unit of a general hospital of Goiás, Brazil. Report books used by nursing staff from the period 2002 to 2007, were analyzed. A total of 230 medication errors were identified, most of which occurred in the preparation and administration of the medications (64.3\%). Medication errors were of omission $(50.9 \%)$, of dose $(16.5 \%)$, of schedule $(13.5 \%)$ and of administration technique $(12.2 \%)$ and were more frequent with antineoplastic and immunomodulating agents (24.3\%) and anti-infective agents (20.9\%). It was found that $37.4 \%$ of drugs were high alert medications. Considering the medication errors detected it is important to promote a culture of safety in the hospital.

Descriptors: Quality of Health Care; Safety Management; Medication Errors.

${ }^{1}$ RN, Ph.D. in Nursing, Adjunct Professor, Faculdade de Enfermagem, Universidade Federal de Goiás, Goiânia, GO, Brazil. E-mail: anaelisa@terra.com.br.

${ }^{2}$ Pharmaceutical, Doctoral Student in Nursing, Escola de Enfermagem de Ribeirão Preto, Universidade de São Paulo, WHO Collaborating Centre for Nursing Research Development, SP, Brazil. Assistant Professor, Faculdade de Farmácia, Universidade Federal de Minas Gerais, MG, Brazil. E-mail: amreis@farmacia.ufmg.br.

${ }^{3}$ RN, Ph.D. in Nursing, Professor, Escola de Enfermagem de Ribeirão Preto, Universidade de São Paulo, WHO Collaborating Centre for Nursing Research Development, SP, Brazil. E-mail: amiasso@eerp.usp.br.

${ }^{4}$ RN, Professor, Faculdade Estácio de Sá de Goiás, Goiânia, GO, Brazil. E-mail: janiaos@gmail.com.

${ }^{5}$ RN, Ph.D. in Nursing, Full Professor, Escola de Enfermagem de Ribeirão Preto, Universidade de São Paulo, WHO Collaborating Centre for Nursing Research Development, SP, Brazil. E-mail: shbcassi@eerp.usp.br.

Corresponding Author:

Ana Elisa Bauer de Camargo Silva

Rua 9, 366, Ap. 301

Setor Oeste

CEP: 74110-100, Goiânia, GO, Brasil.

E-mail: anaelisa@terra.com.br 


\title{
Eventos adversos a medicamentos em um hospital sentinela do Estado de Goiás, Brasil
}

Trata-se de estudo retrospectivo, documental e descritivo que teve como objetivo identificar os eventos adversos a medicamentos, ocorridos no processo administração de medicamentos, e classificar os erros de medicação. Este estudo foi desenvolvido na unidade de clínica médica de um hospital geral de Goiás, Brasil. Foram analisados os livros utilizados pela equipe de enfermagem, no período de 2002 a 2007, para registros de passagem de plantão. Identificaram-se 230 erros de medicação, sendo a maioria no preparo e administração de medicamentos (64,3\%). Os erros de medicação foram de omissão $(50,9 \%)$, de dose $(16,5 \%)$, de horário $(13,5 \%)$ e de técnica de administração $(12,2 \%)$, sendo mais frequentes com antineoplásicos e imunomoduladores (24,3\%) e antiinfecciosos $(20,9 \%)$. Constatou-se que $37,4 \%$ dos medicamentos eram potencialmente perigosos. Considerando os erros de medicação detectados, é importante promover cultura de segurança no hospital.

Descritores: Qualidade da Assistência à Saúde; Gerenciamento de Segurança; Erros de Medicação.

\section{Eventos adversos causados por medicamentos en un hospital centinela del Estado de Goiás, Brasil}

\begin{abstract}
Se trata de un estudio retrospectivo, documental y descriptivo que tuvo como objetivo identificar los eventos adversos causados por medicamentos ocurridos en el proceso de administrarlos y clasificar los errores de medicación. Este estudio fue desarrollado en la unidad de clínica médica de un hospital general de Goiás, Brasil. Fueron analizados los libros utilizados por el equipo de enfermería, en el período de 2002 a 2007, en los registros de traspaso de plantón. Fueron identificados 230 errores de medicación, siendo la mayoría en la preparación y administración de medicamentos (64,3\%). Los errores de medicación fueron de omisión (50,9\%), de dosis $(16,5 \%)$, de horario $(13,5 \%)$ y de técnica de administración (12,2\%), siendo más frecuentes con antineoplásicos e inmunomoduladores $(24,3 \%)$ y antiinfecciosos $(20,9 \%)$. Se constató que $37,4 \%$ de los medicamentos eran potencialmente peligrosos. Considerando los errores de medicación detectados es importante promover una cultura de seguridad en el hospital.

Descriptores: Calidad de la Atención de Salud, Administración de la Seguridad; Errores de Medicación.
\end{abstract}

\section{Introduction}

Adverse drug events (ADEs) have been the focus of studies in various countries, because they occur frequently and increase the morbidity and mortality of patients, becoming new public health problem ${ }^{(1)}$. Adverse drug events (ADEs) cover the adverse reaction to medication (ADR) and medication errors (ME). ME is one of the most frequent types of $A D E$ and has as characteristics the fact that it can be avoided, can occur at any stage of the medication system (prescribing, dispensing and administration of medication) and with any professional of the multidisciplinary team responsible for actions aimed at drug therapy: physicians, pharmacists and nurses ${ }^{(1-2)}$.

The World Health Organization has encouraged all countries in the world to pay more attention to ADEs and patient safety and, in many countries, the discussions and implementation of strategies relating to this thematic are already well advanced. One of the first actions has 
been to encourage the systematization of the collection of detailed information about ADEs, to be analyzed with the aim of planning and implementation of strategies to reduce similar incidents in the future ${ }^{(3)}$.

Internationally, over the past years in several countries, policies and practices for public reporting of ADEs, including MEs, have been developed and implemented. In Brazil, the identification, classification and analysis of ADEs occurring in hospitals are poorly disclosed and governmental actions for the safety of patients are still very tentative, since there are no estimates on the incidence of MEs, their consequences, their causes, nor the direct and indirect costs of these errors for healthcare organizations. Discussions are just beginning, considering that in 2001, a network of sentinel hospitals was established by the Ministry of Health, through the National Agency for Sanitary Surveillance (ANVISA), which were prepared for reporting adverse events and technical complaints regarding health products. However, there is no national database to receive and analyze such events, as few hospitals have a formal system for reporting and analyzing errors.

An overview of the national reality was provided by a pioneer study in three hospitals in Rio de Janeiro which identified a rate of $5.6 \%$ of $\mathrm{ADES}^{(4)}$. The current reality is that many hospitals only identify serious ADEs, which cause great harm to the patient and thereby become public domain. ADEs considered of lesser proportion are not notified due to the lack of procedures aimed at identifying, reporting and recording them, or from fear of exposure and punishment. Ignorance of the rate of ADEs makes it impossible for managers to scale the additional costs imposed on the organization, such as increased length of stay, the request for additional examinations and drugs, not to mention the possibility of procedural actions brought by injured clients. In this context, each hospital must seek information regarding ADEs and MEs and build their own databases with the types, frequencies and causes ${ }^{(5)}$ seeking to transform them into practical improvements to the system through quality programs ${ }^{(6)}$.

There are several ways to identify ADEs in hospitals such as: formal systems of notification of MEs, retrospective review of medical records, direct observation, anonymous reporting combined with observation, analysis of administrative data and interviews with patients and health professionals ${ }^{(5,7)}$. Given the scarcity of formal notification systems in hospitals, the sources of information based on notes describing the assistance that was provided, the clinical evolution, complaints and requests are considered adequate to detect $\mathrm{ADEs}^{(5)}$. When written in a way that portrays the reality, the nursing notes enable ongoing communication that may be intended for different purposes (research, audit, legal processes, planning and others) in addition to providing important information on the quality of care.

Considering that the nursing team remains full time at the hospital, accompanying the patient and that evidence has demonstrated that this professional category is the one that most reports incidents among health professionals(5), it is believed that the records, books, events, made by this team constitute a potential source for identification of ADEs. In this light the objective was to identify in the nursing records of a hospital ward, ADEs that occurred in the process of preparation and administration of medications and classify the MEs detected.

\section{Method}

This was a retrospective, documental, descriptive study with an exploratory design, developed in the Internal Medicine Unit of a general hospital in Goias. The choice of this institution is due to it being part of the Network of Sentinel Hospitals of the National Agency for Sanitary Vigilance and being an area of formation of human resources in health. This hospital gives priority to care, education, research and extramural activities, and is the internship site for various health professional formation centers. It has about three hundred beds, reserved exclusively for patients of the National Health System, in various clinical and surgical specialties. The internal medicine unit was selected because it has 59 beds distributed over thirteen wards with various specialties that treat patients with chronic diseases. It is noteworthy that the institution investigated does not have a notification system for adverse events and their distribution system of medication is the direct individualized drug-dispensing system, with the use of carbon paper copies of the prescription.

Data were obtained from the books used by nursing staff, mainly nurses, in the period 2002 to 2007, which contained shift reports, warnings, internal communications, requests and annotation of intercurrences. The unit of analysis was the nursing register. We analyzed the content of the notes to identify the records related to the occurrence of ADEs. Information concerning the adverse event and the drug involved was recorded in a data collection instrument 
developed by the researchers. The collection was performed in 2007 and 2008 and the sample comprised all 242 notes related to drugs, described in the nursing book of the analysis period.

The pharmacological classification of drugs was performed according to the Anatomical Therapeutic Chemical Classification System (ATC) (level 1 anatomical group) of the "WHO Collaborating Centre for Drug Statistics Methodology", an organ of the World Health Organization(8). The ATC classification, widely used in pharmacoepidemiology, is important because it provides comparison with other investigations and ensures uniformity in the determination of the therapeutic classes. The drugs with a narrow therapeutic index were identified in tertiary source of reference in pharmacotherapy ${ }^{(9)}$. High alert medications - HAMs were classified according to the Institute for Safe Medication Practice (ISMP) ${ }^{(10)}$.

The errors were classified according to the American Society of Hospital Pharmacists (ASHP)(11). The ASHP classifies medication errors as error of prescription (incorrect drug selection, dose, route, concentration, speed of administration, prescription illegible or prescribed orientations that allow errors that harm the patient); error of omission (failure in the administration of a prescribed dose to a patient before the next, if any); error of schedule (administration of medication outside a predefined interval of time of the administration schedule), error of unauthorized medication (administration of medication not prescribed); error of dose (administration of a higher or lower dosage or the prescribed dose in duplicate); error in preparation of the medication (drug formulated or manipulated incorrectly before administration); error of administration technique (procedure inappropriate or administration technique inappropriate); error of drug deterioration (administration of medication past the expiration date or when its physical or chemical integrity has been compromised); error of monitoring (failure in the review of a prescribed regimen to detect problems or failures in the use of laboratory or clinical data to identify the appropriate response of a patient to the therapy); error of adhesion (inadequate behavior of the patient with regard to adherence to a of prescribed drug regimen) and other errors (any error other than those cited in the categories listed previously).

The collected data were entered into a database developed using Epidata 3.1 with validation and consistency checking. Univariate descriptive statistical analysis employing SPSS 15.0 software was performed. The study was conducted after approval by the Research Ethics Committee and authorization from the hospital management.

\section{Results}

After the content analysis of the 242 records related to drugs it was found that 230 (95.1\%) notes had complete information related to the $A D E$, allowing classification of these. Just one note was related to the ADR and was not included in the sample due to insufficient information. The ADEs identified were 230 medication errors (MEs). It is noteworthy that some notes provided information about errors with more than one drug for the same patient or errors of the same medication for various patients. In the temporal evolution analysis of the quantity of ADEs an increase was identified in the numbers of MEs of $247.4 \%$ in 2004 due to the rise from 19 in 2002 to 66 in 2004, as shown in Figure 1.

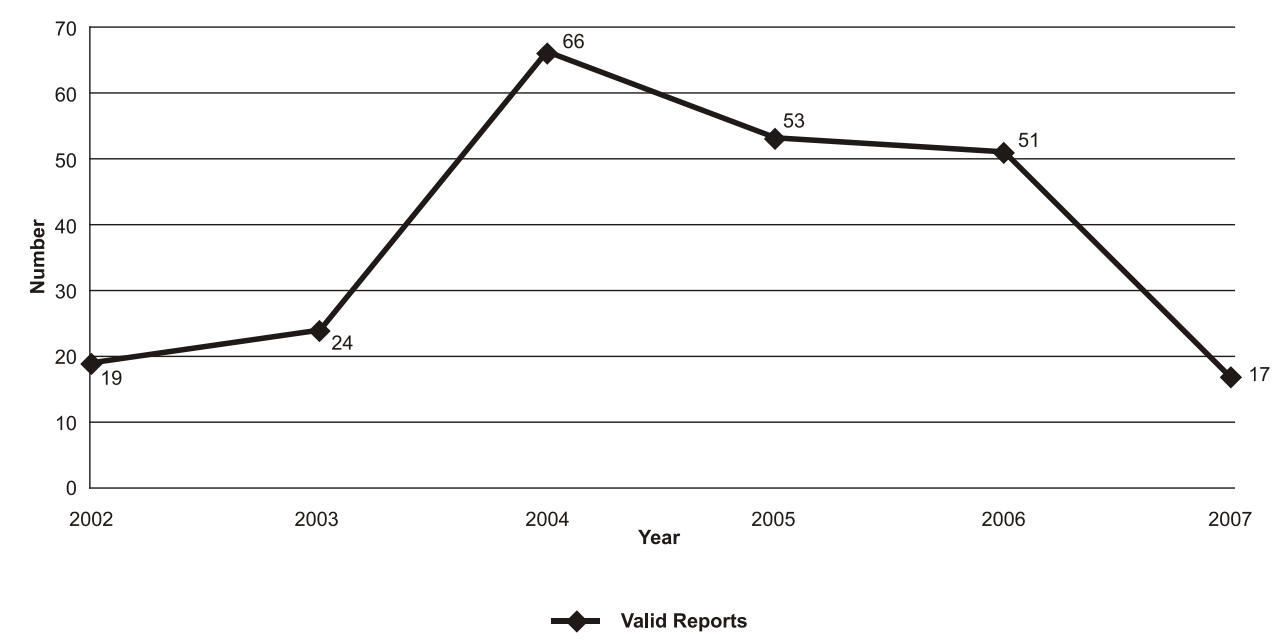

Figure 1 - Annual evolution of the number of medication errors reported in nursing records 
Among the types of MEs classified according to the ASHP(11) the frequency of errors of omission (117; $50.9 \%)$; dose errors $(38 ; 16.5 \%)$ and schedule errors $(31 ; 13,5 \%)$, are highlighted. Table 1 shows the distribution of medication errors identified in the study.

Table 1 - Distribution of MEs reported in the nursing occurrence book classified according to the $\operatorname{ASHP}^{(11)}$. Goiás, Brazil, 2008

\begin{tabular}{lcc}
\hline \multicolumn{1}{c}{ Type of Error } & $\mathbf{n}$ & $\%$ \\
\hline Error of omission & 117 & 50.9 \\
Dose error & 38 & 16.5 \\
Error of schedule & 31 & 13.5 \\
Error of administration technique & 28 & 12.2 \\
Error of unauthorized medication & 15 & 6.5 \\
Error of preparation & 01 & 0.4 \\
Total & 230 & 100 \\
\hline
\end{tabular}

The distribution of MEs according to the subsystems of medication were: preparation and administration of medications (148; 64.3\%), dispensing $(59 ; 25.6 \%)$ and prescription $(23 ; 10.1 \%)$.

Table 2 - Characteristics of the medications involved in MEs Goiás, Brazil, 2008

\begin{tabular}{lcc}
\hline \multicolumn{1}{c}{ Characteristics } & $\mathbf{n}$ & $\mathbf{\%}$ \\
\hline Route of administration of medication & & \\
Parenteral & 153 & 66.5 \\
Oral & 38 & 16.5 \\
Pulmonary & 36 & 0.9 \\
Not reported & 31 & 15.7 \\
Rectal & 01 & 0.4 \\
Total & 230 & 100 \\
ATC classification & & \\
L - Antineoplastic and immunomodulating agents & 56 & 24.3 \\
J - Anti-infective agents for systemic use & 48 & 20.9 \\
B - Blood and Hematopoietic Organs & 35 & 15.3 \\
A - Alimentary Tract and Metabolism & 24 & 10.4 \\
C - Cardiovascular System & 21 & 9.1 \\
N - Nervous System & 10 & 4.3 \\
V - Various & 05 & 2.2 \\
H - Systemic Hormonal preparations, excluding sex & 04 & 1.7 \\
hormones and insulins & & \\
P - Antiparasitic products, insecticides and & 02 & 0.9 \\
repellents & 03 & 1.3 \\
R - Respiratory System & 230 & 100 \\
Report did not permit identification of the ATC class & 22 & 9.6 \\
Total & 37.4 \\
\hline Low therapeutic index Pharmaceuticals & & \\
High Alert Medications & & \\
\hline & & \\
\hline
\end{tabular}

Table 2 presents the characteristics of the drugs involved in MEs. The level 1 groups of the ATC of drugs with greater frequency of MEs were the antineoplastic and immunomodulating agents (56; 24.3\%), antiinfective agents for systemic use $(48 ; 20.9 \%)$ and blood and hematopoietic organs $(35 ; 15.3 \%)$. Regarding the therapeutic index, $43.0 \%$ of the drugs involved in MEs had a low index.
The frequency of potentially dangerous medications was $37.4 \%$ and the errors involving parenteral drugs accounted for $66.5 \%$.

The records found and analyzed did not allow the identification of the consequences and the actions taken by the team in most of the reported adverse events.

\section{Discussion}

The results of this study showed the potential of nursing records as a source of information regarding ADEs and the applicability of this potential in the situational diagnostic, in the risk analysis and in the implementation of improvements to increase patient safety with regard to pharmacotherapy, because $93.9 \%$ of reports where the content was relative to medication, had information about ADEs.

In the literature investigated no study was identified that exclusively employed the nursing records as a source for identifying ADEs. However, a comparative study of sources of information about patient safety showed that ME was the incident most detected on the basis of written records of critical incidents (20.7\%) and in medical record reports $(21.7 \%)^{(5)}$, which explains the results of this investigation.

The ADEs identified in the nursing records were predominantly MEs, and the only ADEs involving an ADR was excluded from the study group due to lack of information. The nurse in their habitual practice identifies and records signs and symptoms of patients, so has adequate conditions to report ADRs. The performance of the nurse in the reporting of ADRs may be improved through educational strategies that demonstrate the importance of this attitude for patient safety, as occurred in Switzerland, resulting in an increase in notification of ADRs by this professional(12).

Analysis of the increase in the number of records in 2004 showed a high prevalence of occurrences related to antineoplastic medication, which occurred due to the centralization of the preparation of antineoplastic agents in the service pharmacy, with systematic changes in their distribution. Considering that the medication administration process involves complex organizational systems, this complexity, together with the large number of drugs administered to patients, creates opportunities for errors. Thus, this elevation of MEs can be explained by the reference of systems theory that emphasizes that any action on part of the system necessarily provokes a reaction from the other parts ${ }^{(13)}$. The redirection of antineoplastic preparation and lack of communication between the subsystems of medication may be factors 
that contributed to the increase in errors as a function of modification to the original system.

Knowledge of the types of errors prevalent in the hospital and its subsystems is key to improving their medication administration process. In this investigation the most frequent errors were errors of omission $(117 ; 50.9 \%)$; dose errors $(38 ; 16.5 \%)$ and schedule errors $(31 ; 13.5 \%)$.

Although errors are detected in higher proportion $(148 ; 64.3 \%)$ in the subsystem of medication administration it is important to highlight the influence of errors in other subsystems, such as dispensing $(59 ; 25.6 \%)$ and prescription $(23 ; 10.1 \%)$, because the errors may reflect the malfunction of the medication system as a whole. It is noteworthy that often the determinant of the error is present in more than one subsystem. In analyzing the content of the records of errors classified as errors of omission and of schedule it was identified that they were related not only to factors intrinsic to the nursing team but also to factors associated with the distribution of medications by the pharmacy and the prescribers (inadequate filling of control forms especially for antimicrobial agents), emphasizing the importance of the systemic approach to optimize security in pharmacotherapy. These results reflect the need to optimize the medication systems of hospital institutions, reviewing the subsystems, reducing steps and simplifying the processes, aiming to reduce medication errors.

Lack of drugs was the main determinant of the errors of omission. It is important to highlight that the unavailability of medication in the hospital pharmacy has external and internal determinants for the institution. To avoid impacts in the system of medication it is important to incorporate modern logistical concepts for materials that prevent the shortage of medications due to internal factors (inadequate planning or use of inefficient management tools). The safety of the care process is compromised by the unavailability of medications, for MEs and ADRs are more likely when a therapeutic approach has to be substituted for reasons unrelated to the clinical needs of the patients ${ }^{(14)}$.

The reports of dose errors $(38 ; 16.5 \%)$ and errors of administration technique $(28 ; 12.2 \%)$ reflected situations of a lack of knowledge about specific medications and of difficulty in handling equipment such as infusion pumps. In the category of error of administration technique one error with death was detected due to intravenous administration of an enteral feeding solution. Prevention strategies of such errors include the expansion of educational measures aimed at the reality of the unit and the adoption of systems of interception of errors ${ }^{(15)}$, such as the use of a single model of infusion pump and of specific syringes for connection to tubes for enteral administration.

The distribution of MEs, considering the pharmaceutical form (Table 2), shows that the medications more associated with errors were those of parenteral use and of oral use. Errors with drugs administered by the parenteral route also presented high frequencies in other studies. The incidence of errors with oral use medications is explained by these being the most prescribed in hospitals ${ }^{(16)}$.

For a better comprehension of MEs in relation to route of administration it is important to analyze the pharmaceutical forms, considering the complexity of administration, the risk of damage and the cost. The pharmaceutical forms classified as higher complexity are, by order, those for intermittent or continuous intravenous infusion, those intended for direct intravenous administration (bolus) followed by those of administration by other routes of parenteral use. The forms of solid and liquid oral use are considered less complex. Regarding the classification of risk of harm to the patient the parenteral forms present major damage and are proportional to the complexity. The pharmaceutical forms not intended for oral or parenteral use are in the classification of lower risk of damage. The order of classification in relation to cost is the same proposal for the complexity of administration(16).

The complexity of the process of parenteral medication administration, involving multiple steps, requires a greater need for adjustments and monitoring throughout the period of administration, increasing the risk of errors(17). To increase safety in medication administration, especially for parenteral medications, the incorporation of information technology applied to health is proposed, through intelligent systems of infusion, bar coding, computerized prescribing and decision support $\operatorname{programs}^{(18)}$.

Analyzing the Level 1 ATC classification, the medications of the antineoplastic and immunomodulator groups $(56 ; 24.3 \%)$, anti-infective agents for systemic use $(48 ; 20.9 \%)$ and blood and hematopoietic organs (35; 15.3\%) were the major therapeutic groups associated with MEs. The significant frequency of errors with antineoplastic agents is a peculiarity of the hospital investigated, because the profiles found by other researchers refer to a higher frequency of errors with antimicrobial agents ${ }^{(2)}$. The concern with MEs involving 
antimicrobials is increasing in the literature because the inappropriate use of this therapeutic class contributes to the emergence of microbial resistance ${ }^{(19)}$.

The nurse, to supervise and execute the activities of drug administration, requires solid knowledge regarding pharmacodynamics, pharmacokinetics, administration techniques, adverse reactions, drug interactions and monitoring parameters of therapeutic response. This knowledge is essential given the diversity of the therapeutic arsenal available in hospitals, which grows every day with the incorporation of new therapeutic classes, new pharmaceutical forms and new drug delivery systems, constituting a risk factor for $\mathrm{MEs}^{(2)}$. The periodic professional update is an adequate antidote to the problem, reducing the gap between the knowledge of the nursing professionals and the demand for their performance in the practice of drug therapy ${ }^{(20)}$.

The lack of knowledge about aspects of pharmacotherapy arises primarily from faulty training in pharmacology applied to practice. Pharmacokinetic aspects, such as the issue of drugs with narrow therapeutic indices, are taught during the graduation without correlation with the issue of ME and risks to patient safety. The same happens with the pattern of ADRs, the intensity of the pharmacodynamic effect and other issues relevant to pharmacotherapy, primarily of high alert medications ${ }^{(2,20)}$.

Although most drugs have a safe therapeutic margin, there are drugs that present an inherent risk of harm to patients when there is failure in their utilization process. These medications are called high alert medications (HAMs). The errors that occur with these drugs are not the more routine, but when they occur, they present high severity and can lead to permanent injury or may be fatal $^{(10)}$. In this study the percentage of errors with HAMs was $37.4 \%$, with the high prevalence of antineoplastic agents. Other frequent HAMs were heparin, insulin, enoxaparin and phenprocoumon. When there is a desire to implement a program for prevention of MEs, one of the groups of drugs that may have preference in this choice are the $\mathrm{HAMs}^{(10)}$.

In Internal Medicine Units is also important to identify the errors with medications with narrow therapeutic indices (MNTIs). The group of MNTIs is comprehensive encompassing some HAMs, certain antibiotics and other drugs, many of oral use. They are medications where the difference between therapeutic and toxic concentrations is very small, necessitating careful monitoring of the dose, of the clinical effects and, sometimes, of the blood concentrations. Especially in the elderly, the errors with these medications can result in hospitalization or prolongation of the hospital stay, when they occur during hospitalization(20). The frequency of errors with MNTIs was $43 \%$. In the study group the mistakes with the following MNTIs highlighted: antineoplastic drugs, heparin, vancomycin, and phenytoin.

The errors of schedule and dose identified in this study should be analyzed carefully. In the case of MNTIs or HAMs these types of errors are worrying, because the safety margin is small. In the case of MNTIs they may generate an error cascade, if it occurs near the day of the plasma monitoring exam. Due to a medication error, the plasma level does not reflect the clinical context of the patient and can lead the physician to perform an inappropriate posological adjustments that may expose the patient to a new adverse event. The errors with HAMs and MNTIs identified in the study represent a threat to safety from using medications, thus, the implementation is recommended of preventive measures, systemic in nature, directed at these groups.

The fact that the records did not indicate what the consequences were of most events, nor the conduct taken as a consequence of what occurred, points to the importance of hospitals having their own system specifically for this purpose, for a multidisciplinary team to execute a deep and thorough analysis of existing problems.

\section{Conclusion}

The present study identified some of the ADEs that occurred in a hospital institution which had a multifactorial and multidisciplinary nature, involving critical medications in relation to patient safety. It also revealed that three adverse events occur on average per month in just one of the inpatient units and that this is a fact to be faced with transparency and with the adoption of urgent actions to correct the existing problems and to construct a medication system safer for everyone. The nursing team are also alerted to the form and content of their notes. Although the records found were incomplete preventing a detailed analysis of the ADEs, this study indicates that in the case of hospitals that have no formal system of notification, the nursing notes constitute a form of written communication of relevant information and may constitute a starting point of the search for and analysis of ADEs.

Given the errors encountered it is believed that hospitals should direct efforts to construct a culture of safety focused on the patient, within which all 
professionals involved in the medication system are conscious of the need for identification, notification and prevention of MEs and that they do this with freedom and systematization, expressing in an open, objective and complete way what happened and how it happened. The notification policy adopted needs to be confidential, through anonymous reporting, so that there is no search for responsibilities and blame, because a punitive culture tends to favor underreporting. It is important to construct a database with information on the frequency, characteristics and causal factors of errors, which may aid in the historical analysis of the incidence of the ADEs. The findings should be disseminated and shared among the various professionals and the various clinics, transforming the errors of one into learning for others, seeking improvements to the system.

It is also necessary that a patient safety committee is instituted in which a multidisciplinary team leads the search for ADEs and adopts methodologies for the analysis of risks to which the patients are exposed, aiming to implement strategies that serve as barriers of protection and prevention of ADEs within the work process. Although many of the reported errors do not bring serious consequences to patients, they should be studied to prevent them happening again and contributing to an increase in the hospital stay, leaving sequels or even leading to death. It also becomes essential that hospitals value the aspects of continued training of its professionals in the pharmacological issues in care practice.

The limitations of this study should be noted, i.e. the sampling from a single hospital, restricting the generalization of the results. It is suggested, therefore, to replicate this research in other hospitals, of different complexities, to increase knowledge of nursing records as a source of information for ADEs and their applicability in patient safety programs.

\section{Acknowledgments}

To the Coordenação de Aperfeiçõamento de Pessoa de Nível Superior (CAPES), Conselho Nacional de Desenvolvimento Científico e Tecnológico (CNPq) and Fundação de Amparo à Pesquisa do Estado de São Paulo (FAPESP).

\section{References}

1. Rommers MK, Teeepe-Twiss I, Guchelaar HJ. Preventing adverse drug events in hospital practice: an overview. Pharmacoepidemiol Drug Saf. 2007;16:1129-35.
2. Tang FI, Sheu SJ, Wei IL, Chen CH.. Nurses relate the contributing factors involved in medication errors. J. Clin Nurs. 2007; 16:447-57.

3. Thomas AN, Panchagnula U. Medication- related patient safety incidents in critical care: a review of reports to the UK national patient safety agency. Anaesthesia. 2008;63:726-33.

4. Mendes W, Martins M, Rozenfeld S, Travassos C. The assessment of adverse events in hospitals in Brazil. Int. Qual in Health Care. 2009;21(4):279-84.

5. Hogan H, Olsen S, Scobie S, Chapman E, Sachs R, McKee $M$, et al. What can we learn about patient safety from information sources within an acute hospital: a step on the ladder of integrated risk management ? Qual Saf Health Care. 2008;17:209-15.

6. Nascimento CCP, Toffoletto MC, Gonçalves LA, Freitas WG, Padilha KG. Indicadores de resultados da assistência: análise dos eventos adversos durante a internação hospitalar. Rev Latino-Am Enfermagem. 2008;16(4):746-51.

7. Song L, Chui WC, Lau CP, Cheung BMY. A 3 - year study of medication incidents in an acute general hospital. J Clin Pharm Therap. 2008;33:109-44.

8. World Health Organization Collaborating Centre for Drug Statistics Methodology. Anatomical Therapeutic Chemical (ATC) index with Defined Daily Doses (DDDs). [access: 2009 July 20]. Available from: http://www. whocc.no/atcddd

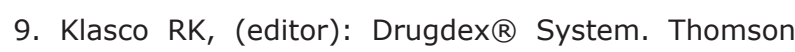
MICROMEDEX, Greenwood Village, Colorado, USA. [access: 2009 July 20]. Available from: http://www. periodicos.capes.gov.br.

10. Institute for Safe Medication Practices. ISMP's list of high alert medic ations. [access 2009 July 20]. Available from: http://www.ismp.org/tools/ highalertmedications.pdf

11. American Association of Hospital Pharmacists - ASHP. Guideline on preventing medication errors in hospitals. Am J Hosp Pharm. 1993;50:305-14.

12. Ulfvarson, J, Mejyr, S, Bergman, U. Nurses are increasingly involved in pharmacovigilance in Sweden. Pharmacoepidemiol Drug Saf. 2007;16:532-7.

13. Reason J. Human error: models and management. BMJ;2000;320:768-70.

14. Landis ELS. Provisional observations on drug product shortages: effects, causes, and potential solutions. Am J Health Syst Pharm. 2002;59:2173-82.

15. Miasso AI, Silva AEBC, Cassiani SHB, Grou CR, Oliveira RC, Fakih FT. O processo de preparo e administração de medicamentos: identificação de problemas para propor 
melhorias e prevenir erros de medicação. Rev. LatinoAm. Enfermagem. 2006;14(3):354-63.

16. Vanderveen T, Harris J, L SR. Reducing complexity: a strategic approach to optimizing the medication use process for all medications. [access 2009 July 20]. Available from http://www.cardinal.com/clinicalcenter/ education/Complexity\%20Dec\%202006.pdf

17. Wirtz V, Katja T, Barber ND. An observational study of intravenous medication errors in the United Kingdom and in Germany. Pharm Word Sci. 2003;25(3):104-11. 18. Bates DW. Preventing medication errors: a summary. Am J Health-Syst Pharm. 2007;64(S9):S3-S9.

19. Bissett, L. Reducing the risk of acquiring antimicrobialresistant bacteria. Br J Nurs. 2006;15(2):68-71.

20. Otero López MJ, Alonso-Hernandez P, MaderueloFernandez JA, Garrido-Corro B, Dominguez-Gil A, Sanchez-Rodriguez A. Acontecimientos adversos prevenibles causados por medicamentos em pacientes hospitalizados. Med Clin. 2006;16(3):81-7. 